\title{
A different suicide attempt in an elderly patient: A case report
}

\author{
Gülhan Kurtoğlu Çelikª, Gül Pamukçu Günaydınª ${ }^{\mathrm{a}}$ Hüsamettin Akküçük ${ }^{\mathrm{b}}$, Yunsur Çevik ${ }^{\mathrm{c}}$, Nurettin Özgür Doğan ${ }^{\mathrm{d}^{*}}$ \\ ${ }^{a}$ Department of Emergency Medicine, Atatürk Training and Research Hospital, Ankara, Turkey \\ ${ }^{b}$ Department of Emergency Medicine, Alanya State Hospital, Antalya, Turkey \\ ${ }^{c}$ Department of Emergency Medicine, Keçiören Training and Research Hospital, Ankara, Turkey \\ ${ }^{d}$ Department of Emergency Medicine, Kocaeli University, Faculty of Medicine, Kocaeli, Turkey
}

\section{ARTICLE INFO}

\section{Article History}

Received $\quad 17 / 05 / 2012$

Accepted $06 / 07 / 2012$

\section{* Correspondence to:}

Nurettin Özgür Doğan

Department of Emergency Medicine,

Faculty of Medicine,

Kocaeli University,

Kocaeli, Turkey

e-mail: nurettinozgurdogan@gmail.com

\section{ABSTRACT}

Depression in the elderly is a common psychiatric disorder, and significantly reduces the quality of life. Suicidal behavior in the elderly varies in a wide spectrum from wish to die to completed suicide. In elderly severe depression may not be diagnosed and unfortunately suicide is the most important complication in this group. The incidence of suicides varies among societies and there is significant difference between the sexes in terms of suicidal behavior. The strong association between depression and suicide attempts in the elderly has been pointed out in many works. The risk of suicide increases with age, regardless of the gender and physical health. Penetrating injuries are more rarely observed than other suicide methods. In this case report, we present an elderly patient with depression who tried a different method of suicide.

J. Exp. Clin. Med., 2013; 30:363-365

\section{Keywords: \\ Depression \\ Elderly suicide \\ Geriatrics \\ Self-stabbing}

\section{Introduction}

The elderly population has increased in the world population and parallel to this increase psychiatric disorders and suicide has gained importance. In the prevention of suicide in the elderly, treatment of psychiatric disorders, particularly including depressive disorder, the resolution of crisis situations and the prevention of social isolation in old age are important (Turan, 2008).

Elderly individuals, have biological, psychological and social problems and changes which interact with each other. These changes may lead to mental disorders in the elderly individuals when they are not properly managed. Major depression is one of the most common disorders (Huuhka and Leinenon, 2011).
Symptoms of depression in the elderly are different from the young population, especially the physical and cognitive symptoms observed in the forefront (Cinar and Kartal, 2008). The incidence of depression among the elderly population is $1-4 \%$. Although the exact incidence of suicide in elderly patients is not known, many of these patients have depression (Cinar and Kartal, 2008). In elderly patients, severe depression may not be diagnosed and unfortunately suicide is the most important complication in this group (Huuhka and Leinonen, 2011). Penetrating injuries are rarely encountered as a method of suicide. Approximately $10.5 \%$ of penetrating injuries are due to suicide. Unfortunately there is not sufficient data about penetrating injuries as a method of suicide in the literature (Ashraf et al., 1996). 


\section{Case report}

A 85-year-old male patient was brought to the emergency department by his relatives after stabbing himself. The patient told that he had taken knife from his own home in the evening, then he had gone to a park in the neighbourhood and tried to stab himself. He could not succeed because he had not enough strength in the right hand. Then he held the knife in his left hand and tried to drive the knife in through lateral archus costa in the left hemithorax with help of a brick with his right hand and injured himself. The patient had history of ischemic stroke and major depression and he was on warfarin therapy because of atrial fibrillation.

On the physical examination, vital signs were stable and the knife was penetrated into the skin and under skin (Fig. 1). General surgery and cardiovascular surgery were consulted. The knife was removed after local wound exploration. It is seen that the knife had penetrated in 5-6 cm laterally through arcus costa and didn't penetrated thorax or abdominal cavity. INR level of the patient was 2.8. Thoracoabdominal computed tomography scan revealed no active bleeding or hemopneumothorax. The patient was discharged after primarily sutured.

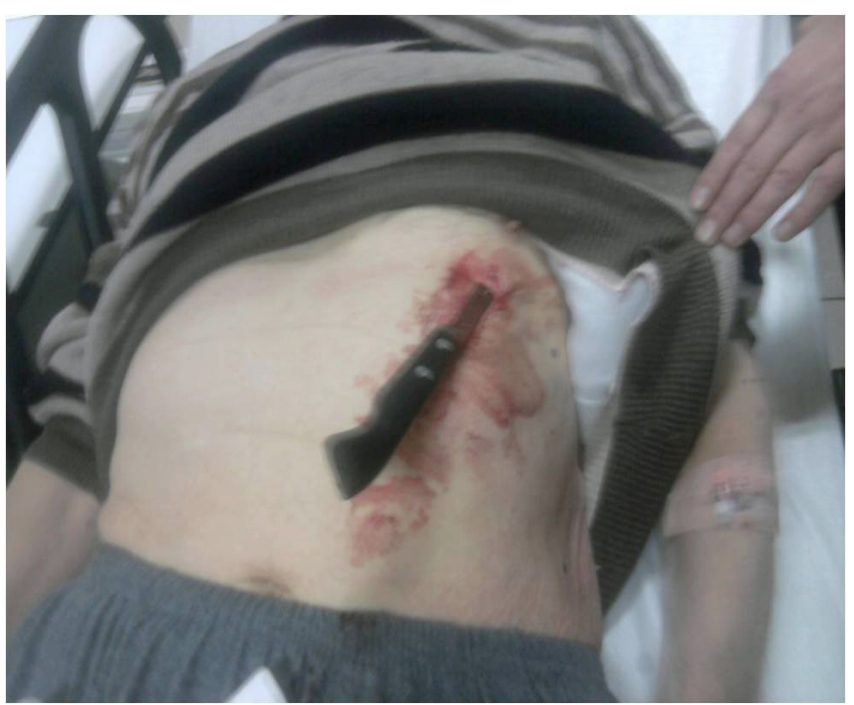

Fig. 1. Stabbed knife at the left hemithorax

\section{Discussion}

Suicide and suicide attempts are important problems in developed and developing countries and present a significant place in young deaths. Suicide and suicide attempts cause a great deal of physical and psychological damage and emergency doctor's knowledge of the phenomena may be helpful for the patients and relatives to obtain psychological help after emergency treatment and to reduce deaths due to suicide. Eliminating the risk factors due to biological, sociological and psychological aspects of suicide is crucial for preventing suicide (Kekec and Yıldırım, 2000).

The patients with suicidal ideation or the ones who attempted suicide are frequently encountered in emergency department. It is quite difficult for emergency physicians to differentiate whether the patient with suicidal ideation is serious or he/she might take those thoughts into action (Kekec et al., 2000).

In our country suicides are most frequent in the range of 15-24 and 25-34 years of age. Women constitute the majority of the suicides under 15 years of age and in 15-24 years of age, whereas the number of men in other age groups is higher (K1zil et al., 2007). There is a more rapid rise in young people than of all ages (Ucan, 2005). According to the results of another study, suicide rates increased with age. The rate of completed attempts increases in men after 45 years of age whereas the rate of completed suicides increases in women after 55 years of age. Suicide attempts are more common in younger patients whereas completed suicides are more frequent in elderly patients. Despite the fact that the elderly constitute $10 \%$ of the total population, the rate of suicides are $25 \%$ more frequent in this age group. The rate of suicides increases three-fold over the age of 75 (Ozsoy and Esel, 2003).

In a study conducted by Pavia et al. (2005) in Italy, the ratio of suicides was $23.7 \%$ in the 45-64 years of age, and $42 \%$ above 65 years of age. Yavuz et al. (2006) study, the ratio of suicide was $29.6 \%$ in the 45-64 years of age group which is similar to Europe and America, and $78 \%$ of the patients were men, the rate of suicides over the age of 65 was $7.4 \%$ which is in accordance with the average of Turkey. The lower rate of suicide among elderly population in our country is thought to be due to influential religious beliefs and sociocultural structure of our country. Another reason for the lower rates of suicide among elderly is the lower rate of the elderly in general population of Turkey in comparison to Europe and America (Yavuz et al., 2006).

The incidence of suicides varies among societies and there is significant difference between the sexes in terms of suicidal behavior. The strong association between depression and suicide attempts in the elderly has been pointed out in many works (Ashraf et al., 1996, Çınar et al., 2008). The risk of suicide increases with age, regardless of the gender and physical health. Situations such as delirium, dementia, stroke history, polypharmacy and major depression may cause suicidal tendencies in old age (Sun et al., 2012). In a study conducted in Turkey with elderly patients with depression, in which the incidence of suicidal ideation, suicide attempts and the desire to die and the relation between these and certain factors constituting risk for depression (socio-demographic characteristics, living alone, negative living conditions, income level) were investigated, it is demonstrated that suicide attempts or suicidal ideation are rare whereas the wish of death is significantly high $(39 \%)$. This result supports the assumption that the presence to wish to die is a sign of depression in the elderly population. The desire to die in elderly depression is important for assessing the risk of suicide (K1zil et al., 2007). Completed suicides are more common among men whereas suicidal ideation and attempts are more common among women. Studies reveal that suicidal attempts ending in death are threefold more in men than women and suicide attempts are four times higher in women than men (Çınar and Kartal, 2008).

Wannan and Fombonne (1998) in a study investigating predisposing factors in suicide attempters admitted to emergency departments observed that $79 \%$ of patients were women and $21 \%$ were men and although women were attempting suicide five times more than men the attempts resulting in death were five times more in men than women. To explain this contradiction he suggests that men are more determined, and they consider expressing that they needed help as a weakness. In our case the efforts of our patient who 
tried to stab himself with help of a brick because he could not succeed by his own power shows his determination to die.

Nguyen et al. (2010) in their study observed that study Vietnam $99 \%$ of cases of suicide were performed by taking drugs and $1 \%$ by using a sharp object. Penetrating patients with the diagnosis of chronic disease and psychiatric illness and their relatives should be warned against the risk of suicide.

Men commonly prefer shotguns, hanging or jumping from height whereas women usually prefer taking high doses of medicine, poisoning or cutting wrists. Men are seen to be more effective in committing suicide by using lethal methods. On the other hand women are commonly unsuccessful to reach a conclusion although they thought committing suicide and even they attempted to (Ozsoy and Esel, 2003). The reasons for using drugs as a method of suicide include the drugs being easy to reach and its being a cheap and painless method. In addition, given that the aim of the majority of suicide attempts is not death but to draw attention, we can understand why using drugs is a preferred method of committing suicide.

Provision of preventive health services and adequate social support for the elderly may reduce the risk of suicide which increase with age. Elderly patients with the diagnosis of chronic disease and psychiatric illness and their relatives should be warned against the risk of suicide.

\section{REFERENCES}

Ashraf, S.S., Volans, A.P., Sharif H., Chaudhry, I., Akhtar, N., Siddiqi, T., Odam, N.J., Grotte, G.J., 1996. The management of stab wounds to the chest: Sixteen years' experience. J. Roy. Coll. Surg. Edinb. 41, 379-381.

Cinar, I.O., Kartal, A., 2008. Signs of depression in the elderly relationship between depression and sociodemographic characteristics. TAF. Prev. Med. Bull. 7, 399-404.

Huuhka, M., Leinonen, E., 2011. Severe and psychotic depression in an elderly person. Duodecim. 127, 390-396.

Kekec, Z., Yıldırım, C., İkizceli, İ., Gönül,, A.S., Sözüer, E.M., 2000. Özkıyım girişimi nedeni ile acil servise başvuran hastalarda hazırlayıcı etkenler. Anadolu Psikiyatri Dergisi. 1, 157-161.

Kızıl, B.T., Yarpuz, A.Y., Ekinci, S., Sorgun, M., Turan, E.D., 2007. Bir geropsikiyatri polikliniğine başvuran depresyonlu yaşlılarda intihar davranışının incelenmesi. Turkish Journal Of Geriatrics.10, 57-60.

Nguyen, T.V., Dalman, C., Le T.C., Nguyen, T.V., Tran, N.V., Allebeck, P., 2010. Suicide attempt in a rural area of Vietnam: Incidence, methods used and access to mental health care. Int. J. Ment. Health Syst. 4, 3.

Ozsoy, S.D., Esel, E., 2003. Suicide. Anadolu Psikiyatri Dergisi. 4, 175-185.

Pavia, M., Nicotera, G., Scaramuzz,a G., Angelillo, I.F., and The Collaborative Group, 2005. Suicide mortality in Southern Italy: $1998-2002$. Psychiatry Resh. 134, 275-279.

Sun, W.J., Xu L., Chan, W.M., Lam, T.H., Schooling C.M., 2012. Depressive symptoms and suicide in 56.000 older Chinese: A cohort study in Hong Kong. Soc. Psychiatry Psychiatr. Epidemiol. 47, 505-514.

Turan, E., 2008. Suicide in particular groups: Elderly suicide. Turkiye Klinikleri J. Psychiatry- Special Topics. 1, 34-39.

Ucan, O., 2005. A study bibliography for publications dealing with suicide in Turkey. Kriz Dergisi 13, 15-26.

Wannan, G., Fombonne, E., 1998. Gender differences in rates and correlates of suicidal behaviour amongst child psychiatric outpatients. J. Adolesc. 21, 371-381

Yavuz, Y., Yürümez, Y., Kucuker, H., Demirel, R., 2006. Investigation of deaths occurring as a result of suicides. General Medical Journal. 16, $181-185$ 